\title{
A dimensão interpessoal da linguagem na variação e na gramaticalização
}

\author{
Edair Maria Görski* \\ Carla Regina Martins Valle ${ }^{* *}$
}

Resumo: Neste artigo discutimos o lugar destinado à dimensão interpessoal e aos interlocutores na Sociolinguística Variacionista (cf. escritos de Labov) e na Gramaticalização (cf. trabalhos de Traugott, Heine e Hopper, entre outros); e questões metodológicas envolvidas nas duas abordagens. Destacamos que, enquanto a sociolinguística laboviana privilegia fatores de estratificação social do falante (em detrimento ao ouvinte), em razão do caráter quantitativo de suas análises, a abordagem funcionalista de gramaticalização como expansão considera a interação falante-ouvinte como motivação para a mudança. Do ponto de vista analítico, apresentamos dois artefatos metodológicos voltados à dimensão interpessoal, e aplicados a um fenômeno em variação e gramaticalização.

Palavras-chave: Contexto comunicativo. Falante-ouvinte. Variação e mudança. Marcador discursivo.

\begin{abstract}
In this paper we discuss the place for the interpersonal dimension and the interlocutors in Variationist Sociolinguistics (cf. Labov's writings) and Grammaticalization (cf. works by Traugott, Heine and Hopper, among others); and methodological issues involved in the two approaches. We emphasize that, while Labovian sociolinguistics favors factors of social stratification of the speaker (to the detriment of the listener), due to the quantitative character of their analyzes, the functionalist approach to grammaticalization as expansion considers the speaker-listener interaction as motivation for change. From the analytical point of view, we presented two methodological artifacts, focused on the interpersonal dimension, and they are applied to a phenomenon in variation and grammaticalization.
\end{abstract}

Key words: Communicative context. Speaker-listener. Variation and change. Discourse marker.

Resumen: Discutimos el lugar para la dimensión interpersonal y de los interlocutores en la Sociolingüística Variacionista (cf. escritos de Labov) y la Gramaticalización (cf. obras de Traugott, Heine y Hopper, entre otros); y cuestiones metodológicas involucradas en los dos enfoques. Es digno de mención que, si bien la sociolingüística laboviana favorece los factores de estratificación social del hablante (en detrimento del oyente), debido al carácter cuantitativo de sus análisis, el enfoque funcionalista de la gramaticalización como expansión considera la

\footnotetext{
* Professora do Programa de Pós-Graduação em Linguística da Universidade Federal de Santa Catarina. http://orcid.org/o00o-0002-0797-1243

** Professora do Departamento de Língua e Literatura Vernáculas da Universidade Federal de Santa Catarina. http://orcid.org/000o-0003-1854-915X
}

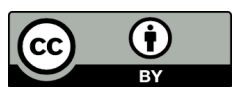


interacción hablante-oyente como motivación para el cambio. Desde el punto de vista analítico, se presentan dos artefactos metodológicos, enfocados en la dimensión interpersonal, y aplicados a un fenómeno de variación y gramaticalización.

Palavras clave: Contexto comunicativo. Orador-oyente. Variación y cambio. Marcador de discurso.

\section{Introdução}

Reportando-nos ao início e meados do século XX, encontramos autores como Otto Jespersen, Edgar Sturtevant, Karl Bühler e Roman Jakobson - os dois últimos vinculados ao Círculo Linguístico de Praga - bastante interessados no papel social da língua na interação entre os membros de um grupo. Sturtevant (1947, p. 3) destaca que "uma língua não pode funcionar normalmente a menos que haja pelo menos dois falantes"'. Bühler (1934) - com base no modelo tradicional de comunicação que envolve o falante, o ouvinte e o mundo - propõe que a linguagem tem, respectivamente, três funções: expressiva (o falante manifesta uma atitude em relação àquilo de que fala), apelativa (o falante visa uma reação do ouvinte) e representativa (o falante veicula através da língua o mundo exterior e interior). Em relação a Jespersen, Labov (2008 [1972], p. 304) sinaliza que "encontramos ao longo de toda a sua obra uma preocupação com as funções expressivas e diretivas da língua que entra fortemente em suas discussões sobre a mudança linguística”. Jakobson (1974), por sua vez, expande as funções triádicas bühlerianas para seis: emotiva (centrada no emissor), conativa (centrada no receptor), referencial (centrada no assunto), poética (centrada na mensagem), metalinguística (centrada no código) e fática (centrada no canal). Sob uma ótica distinta, Halliday e Hasan (1976) distinguem três componentes funcionais no sistema linguístico: ideacional (a função da linguagem é de organizar a experiência e a interpretação do real), interpessoal (a linguagem serve para expressar atitudes e julgamentos do falante e

\footnotetext{
${ }^{1}$ No original: "a language cannot function normally unless there are at least two speakers of it". (As traduções ao longo do texto são de nossa responsabilidade.)
} 
estabelecer relações entre as pessoas) e textual (o falante tem a capacidade de criar e reconhecer unidades textual e situacionalmente coerentes).

Essa contextualização inicial com foco nas funções da linguagem se justifica pelo fato de que (i) tanto na Sociolinguística Variacionista quanto na Gramaticalização há autores representativos que evocam as funções da linguagem ao discutirem questões de variação e mudança; e (ii) as funções centradas no falante e no ouvinte estão diretamente relacionadas à dimensão interpessoal da linguagem, que diz respeito a relações estabelecidas entre os interlocutores numa situação comunicativa, envolvendo aspectos socioestilísticos e discursivo-pragmáticos - foco da discussão proposta neste artigo como um ponto de aproximação, mesmo que não central, entre a Sociolinguística Variacionista e a Gramaticalização. ${ }^{2}$

O artigo se organiza em duas seções, além da Introdução e das Considerações finais: (i) na primeira seção a) discorremos sobre a visão laboviana acerca de variação estilística e social, buscando evidenciar o componente interpessoal nessa abordagem, e b) apresentamos e aplicamos, a título de ilustração, um artefato metodológico multidimensional construído para captar relações interpessoais em uma análise variacionista de marcadores discursivos; e (ii) na segunda seção a) contemplamos o componente interpessoal presente em estudos funcionalistas de gramaticalização, e b) apresentamos e aplicamos, também em caráter ilustrativo, uma variável independente complexa elaborada para medir graus de mudança categorial envolvidos em um fenômeno de natureza interacional em gramaticalização.

\section{A dimensão interpessoal na Sociolinguística Variacionista}

\footnotetext{
${ }^{2}$ A convergência entre variação e gramaticalização se dá, primariamente, pela concepção de que variação e mudança são inerentes à língua, pela aproximação entre as noções de variável linguística e domínio funcional, lugar onde as formas coocorrem e concorrem entre si, pelo papel atribuído à frequência de uso, entre outros aspectos (cf. TAVARES; GÖRSKI, 2015; GÖRSKI; TAVARES, 2017).
} 
A Sociolinguística Variacionista, cujo representante seminal é William Labov, focaliza primordialmente a estrutura linguística em relação com a estrutura social de uma comunidade, buscando estabelecer amplas correlações entre variáveis linguísticas e macrocategorias sociais (faixa etária, sexo, escolaridade, classe social, etnia), de modo a depreender padrões sociolinguísticos regulares de variação. O significado social corresponde a "traços da língua que caracterizam vários subgrupos numa sociedade heterogênea" (LABOV, 2008 [1972], p. 313), e o significado estilístico - associado ao domínio cognitivo de graus de atenção à fala que se refletem em diferentes níveis de formalidade - corresponde a "alternâncias pelas quais um falante adapta sua linguagem ao contexto imediato do ato de fala" (LABOV, 2008 [1972], p. 313). É da dimensão estilística que Labov extrai a noção de vernáculo, entendido como "estilo em que se presta o mínimo de atenção ao monitoramento da fala" (LABOV, 2008 [1972], p. 244). É nesse estilo, segundo o autor, que se observam padrões linguísticos mais regulares e onde se obtêm os dados mais sistemáticos para a análise da estrutura linguística, por isso o vernáculo - associado à fala casual produzida em entrevistas sociolinguísticas - é tido como o estilo contextual por excelência para o estudo de fenômenos variáveis. Como, porém, ao longo de uma entrevista diferentes contextos estilísticos se mesclam em decorrência de diferentes graus de atenção prestada à fala, alternâncias estilísticas ocorrem sistematicamente durante esse evento comunicativo, distribuindo-se num continuum unidimensional correlacionado a diferentes graus de formalidade. É nesse cenário que se desenvolvem os estudos da chamada primeira onda variacionista $\left(\right.$ ECKERT, 2012, 2016) ${ }^{3}$, fase em que a variação estilística, atrelada a alternâncias de estilo na entrevista, tem um lugar secundário, interessando à medida que se correlacione com a variação social para o estabelecimento de padrões de regularidade estrutural.

Labov postula que "não existe falante de estilo único" (2003 [1969], p. 234) e evoca o contexto imediato do ato de fala ao tratar de estilo, admitindo que as trocas estilísticas são motivadas pelas relações do falante com o ouvinte ou a audiência, e particularmente pelas relações de poder e solidariedade entre eles; pelo contexto social mais amplo, os

\footnotetext{
${ }^{3}$ Eckert (2012, 2016), tomando como critério o significado social, sistematiza os estudos variacionistas em três ondas, que, embora guardem uma certa cronologia, não são excludentes, pois representam diferentes visões acerca do significado social da variação.
} 
domínios da escola, emprego, casa, vizinhança, igreja etc.; e pelo tópico. $\mathrm{O}$ autor reconhece, portanto, o papel desempenhado pelo contexto imediato do ato de fala em sua concepção de variação estilística, contudo, metodologicamente, em seus estudos restringe a variação estilística ao escopo da entrevista sociolinguística; e propõe relacionar o comportamento linguístico com a medição de status atribuído (filiação étnica e religiosa, casta, sexo, família etc.) e de status adquirido (educação, renda, profissão e, possivelmente, pertencimento a grupos de pares) - fatores associados ao falante, que, segundo ele, são mais facilmente mensuráveis do que aqueles concernentes ao contexto de fala. Tendo como interesse central o estabelecimento de padrões regulares de uso, abstraídos de manifestações linguísticas individuais, Labov afirma existirem evidências que mostram que "a maioria das mudanças em andamento acompanham significativas distribuições sociais antes de registrarem qualquer alteração estilística" (LABOV, 2008 [1972], p. 327). Assim, nos estudos labovianos o que ganha destaque é a estratificação social da linguagem, e é, de acordo com o autor, em variáveis sociais bem estabelecidas que a alternância de estilo, provocada por diferentes graus de atenção à fala, é atestada. Parece, pois, ficar fora do campo de interesse da sociolinguística variacionista laboviana a variação estilística correlacionada diretamente às relações estabelecidas entre os participantes de um evento comunicativo - que envolvem os papéis sociais dos interlocutores e elementos do contexto situacional e sociocultural, ou seja, relações que extrapolam os limites internos da entrevista sociolinguística -, já que os dados relevantes para análise costumam se restringir à fala produzida pelo informante.

Embora privilegie a estratificação social do falante quanto a fatores extralinguísticos, Labov, em diversas passagens de seus escritos, evoca, direta ou indiretamente, as funções tripartites da linguagem nos termos de Bühler (1934) representacional, expressiva e apelativa -, centradas, respectivamente, na terceira, na primeira e na segunda pessoa do discurso. Inicialmente, Labov (1978) toma o significado representacional (ou o "estado de coisas") como primário e considera a função de identificação do falante e a de acomodação ao ouvinte como secundárias e subordinadas à função representacional. Posteriormente, Labov (2010) contrasta as funções representacional e social, esta recobrindo tanto a função expressiva - que fornece 
informações sobre a identificação do falante (seu estado emocional, idade, sexo/gênero, etnia, status socioeconômico, identidade local) - como a diretiva/apelativa - que envolve acomodação à audiência (adequação ao grau de distância social, polidez e deferência, troca de estilo e audience design). Continua, porém, postulando que as categorias sociais gênero e classe social são mais relevantes para a difusão da mudança, do que, por exemplo, etnia, identidade local, redes sociais e comunidades de práticas.

É possível depreender dos textos de Labov, que (i) a função diretiva/apelativa da linguagem fica esmaecida no que se refere à variação e mudança linguística, pois mesmo quando o autor fala sobre acomodação à audiência, mencionando fatores como distância social e polidez (esperando-se, pois, que ele relacione claramente a variação estilística a essa função), ele deixa de tratar desses fatores para salientar o papel de fatores sociais concernentes à estratificação do falante na difusão da mudança; (ii) a variação estilística, decorrente de graus de atenção à fala, tem papel secundário no processo de mudança e só interessa enquanto correlacionada à variação social para o estabelecimento de padrões de regularidade estrutural (GÖRSKI; VALLE, 2014); e que (iii) a natureza quantitativa das análises variacionistas direciona o olhar do pesquisador para o falante estratificado em macrocategorias sociais, em detrimento do ouvinte e do contexto comunicativo.

Não obstante o modus operandi de Labov no que se refere à tênue menção à audiência no estudo da variação linguística, alguns trabalhos variacionistas que se identificam, em alguma medida, com a linha laboviana têm buscado alternativas metodológicas para captar a relação entre os interlocutores de uma situação comunicativa e avaliar seu efeito sobre a realização de fenômenos linguísticos variáveis. ${ }^{4}$ A título de ilustração, expomos brevemente a construção do artefato metodológico

\footnotetext{
${ }^{4}$ Nosso interesse é por trabalhos que partem da linha laboviana e ampliam a metodologia para o tratamento da variação socioestilística ao contemplar a relação falante-ouvinte. Nesse sentido, não vamos considerar aqui estudos variacionistas desenvolvidos na perspectiva de audience design (cf. BELL, 2001), nem aqueles que apresentam um forte componente antropológico e cultural, que são associados à segunda e terceira onda variacionsita (cf. ECKERT, 2012, 2016, 2018), ou ainda os que tomam a interação social como foco primário de estudo (cf. SACKS; SCHEGLOFF; JEFFERSON, 1974).
} 
voltado a relações interpessoais em um estudo variacionista realizado com entrevistas sociolinguísticas5 (cf. VALLE, 2014).

Interessada no uso variável dos marcadores discursivos (MDs) derivados de verbos de cognição sabe? e entende ${ }^{6}$ - utilizados como requisitos de apoio discursivo, cf. (1) - , Valle (2014) parte da hipótese de que nem sempre a relação entre os participantes da entrevista (entrevistador e entrevistado) e as dinâmicas de interação são do mesmo tipo em todas as entrevistas, e isso pode impactar o uso de elementos que atuam tipicamente na dimensão interpessoal, como é o caso dos MDs em pauta.

(1) F: Não é que:: eu não gosto muito de trabalhar como público assim, sabe?... mas também não gosto de ficar olhando pra parede assim, sabe? é uma coisa assim, eu gostaria de pegar um:: vamos supor... um:: um escrito::rio, alguma coisa digialguma coisa digitan::do...(est) entendeu? uma coisa mais assim que- que distraia que:: e que eu goste mesmo, né? o próximo eu vou procurar fazer o que eu gosto assim, sabe?... porque eu não quero entrar:: é ruim assim tu entrar pensando só no dinheiro... (E: É.) sabe? não rende, sabe? tu fica muito pouco, é ruim assim, eu não quero, eu quero fazer o que eu gosto, não eu tô bem onde eu tô:: e eu vou continuar, sabe?... (est) é:: não faço assim. (VALLE, 2014, p. 66)

\title{
Consideramos que
}

\begin{abstract}
as entrevistas sociolinguísticas apresentam estruturas diferentes a depender do estado emocional do falante, da relação de proximidade entre entrevistadorentrevistado e da situação de entrevista, dentre outros aspectos. Algumas delas enquadram-se no formato mais fixo proposto por Labov, mas, em outras, há o rompimento do padrão pergunta-resposta e o entrevistador tem seu papel de comando diminuído, o que instaura uma situação de diálogo semiespontâneo. (VALLE; GÖRSKI, 2016, p. 31)
\end{abstract}

Nesse sentido, a entrevista é considerada como "locus de um jogo comunicativo dinâmico" (GÖRSKI; VALLE, 2014, p. 83), que envolve negociação de significados entre

\footnotetext{
${ }^{5}$ As entrevistas analisadas foram realizadas com moradores da Barra da Lagoa, Florianópolis/SC comunidade não urbana, formada originariamente por famílias de pescadores - e compõem a amostra Brescancini-Valle 2001-2010, a qual integra o Banco de Dados VARSUL (www.varsul.org.br).

${ }^{6}$ Os marcadores sabe? e entende? são tomados como macroformas que recobrem, respectivamente: sabe?, sabes?; e entendeu?, entende(s)?,(es)tá(s) entendendo?, (en)tendesse?. Tais itens são elementos multifuncionais que atuam tanto no plano interacional, solicitando a atenção do ouvinte, quanto no textual, apontando para certas partes do texto, na função de focalização (VALLE, 2001; 2014).
} 
os interlocutores, permitindo captar a variação estilística em relação à interação entre os participantes.

Para lidar metodologicamente com as diferenças entre as entrevistas, Valle (2014) propõe inicialmente três grupos de fatores - relação de proximidade entre os interlocutores, proatividade do falante e envolvimento emocional do falante - e, posteriormente, integra-os em uma única variável independente complexa denominada configuração da entrevista. Diferentemente do que estabelece Labov (2008 [1972]; 2001) para o tratamento da variação intrafalante ${ }^{7}$, a referida variável complexa é aplicada a cada entrevista como um todo (como é feito com os fatores sociais), de modo que diferenças nos usos variáveis dos marcadores são associadas não a estilos contextuais intraentrevista, mas ao tipo de configuração de cada entrevista, que envolve não só o falante mas também o ouvinte.

O primeiro grupo, relação de proximidade entre os interlocutores, é ele próprio complexo, sendo constituído por fatores que resultam da aplicação de quatro critérios considerados em relação à díade entrevistador-entrevistado: simetria de sexo, simetria de idade, simetria de escolaridade e pertencimento à comunidade ${ }^{8}$. Cada um desses critérios é pontuado com zero ou o,5, a depender do grau de simetria: mesmo sexo, idade aproximada, escolaridade aproximada e integrantes da mesma comunidade recebem o,5 cada um, de modo que o somatório fornece valores entre zero e 2,o. Tal pontuação serve de base para estabelecer três fatores integrados para o grupo relação de proximidade entre os interlocutores: proximidade maior (entre 1,5 e 2,0); proximidade intermediária $(1,0)$; e distanciamento (entre zero e 0,5$)$.

O segundo grupo, proatividade do falante, é formado por dois fatores: segue o script e vai além do script. O entrevistado segue o script quando se limita a responder as perguntas, sem propor novos tópicos; e vai além do script quando, além de responder, introduz tópicos de seu interesse, atribuindo à entrevista um caráter de interação efetiva.

\footnotetext{
${ }^{7}$ Labov propõe dois métodos para análise estilística na entrevista: (i) segmentação da entrevista em estilos contextuais que vão da fala casual até a leitura de textos e de palavras (LABOV, 2008 [1972]); e (ii) aplicação do modelo da árvore de decisão, identificando oito contextos divididos nos eixos da fala casual - narrativa, grupo, infância e tangente -, e da fala cuidada - resposta, língua, soapbox e residual (LABOV, 2001). Ambos os métodos seguem o critério cognitivo de atenção à fala.

${ }^{8} \mathrm{~A}$ amostra Brescancini-Valle foi coletada por duas entrevistadoras, uma integrante da comunidade e outra de fora, daí a pertinência de ser considerado o critério pertencimento à comunidade.
} 
O terceiro grupo, envolvimento emocional do falante, contém dois fatores: emocionalmente envolvido e neutro. A presença de momentos de desabafo ou descontração, acompanhados de gestos expansivos, alteração do tom, uso de palavrões, choro, riso etc., indica que o entrevistado está emocionalmente envolvido; na ausência dessas pistas é considerado neutro. ${ }^{9}$

Esses três grupos de fatores, além de serem testados de forma independente por meio do pacote estatístico GoldVarbX (SANKOFF; TAGLIAMONTE; SMITH, 2005), são posteriormente reunidos numa única variável independente complexa de caráter multidimensional, de modo a permitir uma visão mais global da configuração de cada entrevista. Para essa etapa analítica, os fatores dos dois últimos grupos também recebem pontuação, de modo que na codificação dos dados cada grupo de fatores se converte em um valor numérico cuja pontuação máxima é 2,o (cf. Quadro 1). Desse arranjo resulta uma pontuação gradiente distribuída entre 2,0 e 6,0 pontos, que indica se a entrevista estaria mais para os moldes tradicionais (pontuação mais baixa) ou mais para conversa cotidiana (pontuação mais alta). Em suma, cada entrevista é identificada com um desses valores numéricos, operacionalizados como fatores multidimensionais que agregam um conjunto de traços, e o uso alternado dos marcadores é correlacionado a esses valores.

Quadro 1: Pontuação dos fatores que compõema variável complexa configuração da entrevista

Relação de proximidade entre os interlocutores

Resultante do somatório de quatro critérios: simetria de sexo, simetria de idade, simetria de escolaridade e pertencimento à comunidade (o ou o,5 para cada critério):

Entre 1,5 e 2,0 - Proximidade maior

1,0 - Proximidade intermediária

Entre zero e o,5 - Distanciamento

Proatividade do falante

2,0 - Vai além do script

1,0 - Segue o script

Envolvimento emocional do falante

2,o - Emocionalmente envolvido/empolgado

1,0 - Neutro

Fonte: Adaptado de Valle (2014, p. 316)

\footnotetext{
${ }^{9}$ Os grupos de fatores proatividade e envolvimento emocional do falante aproximam-se, em certa medida, do que Labov (2001) classifica como tangente e do que Labov (2008 [1972]) propõe como narrativa de experiência pessoal e pistas do canal.
} 
A expectativa da autora em sua pesquisa era de que quanto maior fosse a relação de proximidade entre os interlocutores, a proatividade e o envolvimento emocional do falante, ou seja, quanto mais a entrevista se aproximasse de uma conversa cotidiana, maior seria o uso de elementos de interação com o interlocutor, especialmente do marcador entende? (e suas diferentes formas de realização), tido como mais voltado para o plano interacional do que sabe?, especialmente por ainda reter vestígios de flexão (entendeu?, entende(s)?, (es)tá(s) entendendo?, (en)tendesse?). Os resultados probabilísticos atestaram essa hipótese, mostrando uma tendência de uso de entende? nas entrevistas mais próximas de conversa e, em contrapartida, uma tendência de uso de sabe? nas entrevistas nos moldes mais tradicionais. Nesse estudo, por reunirem simultaneamente diferentes componentes de natureza interpessoal envolvidos na situação de entrevista, os resultados associados à variável complexa configuração da entrevista se mostraram mais robustos e consistentes do que os resultados obtidos para cada um dos três grupos de fatores isoladamente.

Outros trabalhos, como o de Coelho e Nunes de Souza (2014) - que analisa as formas de tratamento ( $t u$, você, o senhor) em peças de teatro florianopolitanas dos séculos XIX e XX - e o de Reis (2003) - que analisa a correlação entre o grau de força manipulativa e o uso das formas verbais indicativa e subjuntiva na expressão variável do modo imperativo em diálogos entre personagens do romance Vinhas da Ira -, também propõem variáveis socioestilísticas complexas que contemplam, concomitantemente, características dos dois interlocutores, de modo a verificar se os diferentes papéis sociais desempenhados nas díades locutor-interlocutor - para além de relações simétricas e assimétricas - estariam refletidos na variação estilística. Nesses casos, como as relações sociopessoais envolvem não apenas o papel de cada interlocutor e suas características pessoais, mas também a rede social mais ampla em que estão inseridos (em ambiente familiar, religioso, policial etc.), o tipo de relação estabelecida entre os participantes é 
definida contingencialmente a cada ocorrência analisada, considerando sempre os pares em interação. ${ }^{10}$

Essa breve revisão de trabalhos ilumina alguns caminhos metodológicos que podem ser trilhados para a construção de ferramentas analíticas aplicáveis à dimensão interpessoal da linguagem em diferentes tipos de interação, na fala e na escrita. No caso, tanto entrevistas sociolinguísticas como peças de teatro e romance se mostram gêneros discursivos nos quais, por diferentes instrumentos metodológicos, é possível observar a atuação multidimensional de um conjunto de fatores associados aos interlocutores sobre fenômenos linguísticos variáveis. A variação estilística, assim abordada, deixa de ser analisada apenas a partir do critério cognitivo de atenção à fala, e passa a ser contemplada também pela via discursiva que contempla a dimensão interpessoal da linguagem.

Até este ponto, evocamos estudos que buscaram encontrar padrões socioestilísticos de usos variáveis a partir de análises quantitativas, com o diferencial metodológico de caráter multidimensional refletido na elaboração de variáveis independentes complexas, seja por resultarem de um conjunto de grupos de fatores gradientes integrados, seja por envolverem fatores robustos aplicados simultaneamente ao par de interlocutores, de modo a retratarem a dinâmica das relações sociais que se altera em cada díade interacional.

Vale pontuar ainda que no âmbito da Sociolinguística Variacionista, na esteira dos estudos de terceira onda, o significado social vem incorporando novos ingredientes que mesclam aspectos ideológicos e socioculturais, com foco na língua como prática social e na agentividade do falante que, criativa e distintivamente, projeta personas e (re)cria identidades em suas práticas estilísticas, numa dinâmica em que cenários micro e macrossociológicos se articulam dialeticamente (cf. ECKERT, 2016, 2018). Como nosso foco neste artigo é a dimensão interpessoal no escopo de eventos comunicativos que

\footnotetext{
${ }^{10}$ Fazemos menção a esses estudos aqui em virtude de analisarem amostras escritas, mas, por uma questão de espaço, não vamos descrever a composição dessas variáveis e remetemos o leitor interessado às referências indicadas.
} 
envolvem, em alguma medida, interlocutores em contextos dialogais, deixamos de abordar noções como agentividade e (re)construção de identidades, que são permeadas por aspectos fortemente subjetivos e ideológicos. Não estamos, com isso, ignorando o fato de que todo discurso é atravessado por subjetividades e ideologias, mas apenas delimitando o terreno em que nos propomos a considerar a dimensão interpessoal da linguagem, com foco principalmente em aspectos de natureza discursivo-pragmática, mantendo os aspectos sociais mais amplos como pano de fundo.

\section{A dimensão interpessoal na Gramaticalização}

Em uma abordagem funcionalista da linguagem, inerentemente cognitivocomunicativa, a dimensão interpessoal naturalmente se faz presente. A língua cumpre, além das tarefas principais de representação mental da experiência e de comunicação, outras importantes funções metacomunicativas, a saber: a) a função de coesão sociocultural - a língua atua mantendo um grupo unido e identificando indivíduos com o grupo; b) a função afetiva/interpessoal - a língua medeia a interação entre os membros de um grupo, podendo sinalizar relações de afeto, cooperação, obrigação, dominância ou competição; c) a função estética - a língua expressa valores estéticos em discursos, ficção, poesia, canções, peças teatrais (GIVÓN, 1993). Para os propósitos deste artigo, interessam-nos particularmente a função de representação/comunicação ${ }^{11}$ e a função interpessoal.

Nessa perspectiva, o uso rotinizado de certas estratégias discursivas em situações de comunicação é que vai moldando e remoldando a gramática, que reflete em sua estrutura as experiências dos falantes com a língua (BYBEE, 2006). Ao convencionalizar os usos mais frequentes - o que vai libertando gradativamente a linguagem

\footnotetext{
${ }^{11} \mathrm{Na}$ perspectiva funcionalista assumida, fica implicado que, inerentemente associada à função comunicativa (discursiva - de ordem pragmática), existe uma função cognitiva (de representação do conhecimento/da experiência - de ordem semântica).
} 
gramaticalizada da total dependência do contexto comunicativo ${ }^{12}$, a relação originariamente icônica entre formas e funções vai se tornando relativamente arbitrária (GIVÓN, 2002).

O foco no movimento do discurso para a gramática é acentuado por Hopper (1987), ao propor que a gramática é sempre emergente. O autor sugere que (i) regularidades observadas na língua partem do discurso, são moldadas pelo discurso e, em um processo cíclico, passam a remoldar o discurso; (ii) formas e construções são maleáveis, flexíveis e forjadas na negociação face a face entre os participantes da comunicação, levando em conta suas avaliações e experiências linguísticas; e (iii) a noção de gramática, mais bem entendida como devir, deveria ser substituída pela noção de gramaticalização.

Na literatura mais recente sobre gramaticalização (cf. TRAUGOTT, 2010a; HEINE, 2018, entre outros), os estudos sobre esse tipo de mudança têm sido distribuídos em dois grupos, a depender de como a gramaticalização é vista: (i) como processo que envolve perdas, reduções, congelamento, dependência e obrigatoriedade, com foco na forma do elemento em gramaticalização, considerando um escopo estrutural (cf. GIVÓN, 1979; LEHMANN, 1995; entre outros) - numa visão mais restrita; (ii) como processo que envolve ganhos e expansão, com foco na função do elemento em gramaticalização num dado contexto, considerando um escopo discursivo (cf. HIMMELMANN, 2004; DIEWALD, 2006; WALTEREIT; DETGES, 2007; TRAUGOTT, 1995, 2002, 2008; BRINTON; TRAUGOTT, 2005; entre outros) - numa visão mais ampla.

Essa divisão dicotômica é, porém, questionada por Heine (2018), que reitera a defesa de uma abordagem unificada que contemple processos de expansão e de redução (cf. HEINE; CLAUDI; HÜNNEMEYER, 1991; HEINE; KUTEVA, 2007; entre outros) - numa perspectiva que leve em conta a interação de fatores pragmáticos, semânticos, morfossintáticos e fonéticos, associados, respectivamente, aos parâmetros de extensão,

\footnotetext{
${ }^{12}$ Contexto comunicativo, segundo Givón (2002), envolve compartilhamento: do discurso/texto corrente, da situação de fala e do conhecimento genérico-cultural. Heine et al. (2013), por sua vez, ao proporem uma Gramática do Discurso, listam os seguintes componentes de uma situação de discurso: organização do texto, fonte da informação, atitudes do falante, interação falante-ouvinte, contexto situacional e conhecimento de mundo. Em um dado ato de fala, alguns desses componentes podem ganhar relevo enquanto os demais permanecem como fundo.
} 
dessemantização, decategorização e erosão, propostos por Heine e Kuteva (2017), como ferramentas para identificar instâncias de gramaticalização que ocorreriam diacronicamente nessa ordem. Os autores admitem que a extensão é o parâmetro mais complexo, uma vez que envolve (i) um componente sociolinguístico - a gramaticalização começa com uma inovação individual (novo uso de uma forma já existente) que vai sendo replicada por outros falantes até atingir uma comunidade inteira (envolve emergência e propagação); (ii) um componente pragmático-textual - a expansão se dá de um contexto usual para um novo contexto, espalhando-se gradualmente para paradigmas mais gerais; e (iii) um componente semântico - um significado existente se altera para outro que é sustentado pelo novo contexto.

Em consonância com o objetivo deste artigo, a faceta do processo de gramaticalização que melhor respalda nosso enfoque é a que diz respeito à expansão (levando-se em conta que todo ganho naturalmente envolve alguma perda). Nesse tipo de abordagem, são considerados aspectos como: a) a participação ativa dos indivíduos como criadores de novos usos, especialmente em contextos dialogais e dialógicos, com fortalecimento pragmático de itens e construções e com reinterpretação induzida pelo contexto, podendo envolver instâncias de (inter)subjetivização (cf. TRAUGOTT, 1995, 2002, 2008; 2010b; TRAUGOTT; DASHER, 2002; HOPPER; TRAUGOTT, 2003) b) microalterações de significado com expansão contextual, envolvendo mudanças metonímicas e metafóricas na direção concreto > abstrato (cf. HEINE; CLAUDI; HÜNNEMEYER, 1991; HEINE; KUTEVA, 2007; HEINE, 2018); e c) o papel da frequência na rotinização e convencionalização de novos usos (cf. BYBEE, 2006); entre outros aspectos.

Já em suas primeiras definições, Traugott (1995) insere um componente adicional na visão clássica de gramaticalização como mudança do léxico para a gramática, ao destacar os contextos pragmáticos e morfossintáticos altamente específicos em que esse processo ocorre'³. Hopper e Traugott (2003), dando relevo à ideia de mudança (em vez

\footnotetext{
13 "Gramaticalização é o processo pelo qual material lexical, em contextos pragmáticos e morfossintáticos altamente específicos, torna-se gramatical [...]" (TRAUGOTT, 1995, p. o1). No original: "Grammaticalization is the process whereby lexical material in highly constrained pragmatic and morphosyntactic contexts becomes grammatical [...]"
} 
de processo) e de novas funções (em vez de funções mais gramaticais) ${ }^{14}$, salientam como motivação para a gramaticalização o papel dos interlocutores na negociação de significados mediante estratégias comunicativas utilizadas na produção e compreensão durante a interação verbal. Nesse sentido, "a mudança é resultado de interação estratégica, especificamente de escolhas feitas por parte dos falantes/escreventes na negociação interacional com os ouvintes/leitores" 15 (TRAUGOTT, 2002, p. 21).

Traugott $(2008 ; 2010 b)$ sugere que contextos dialogais, em que há trocas de turno, e contextos dialógicos, em que múltiplos pontos de vista são invocados na situação de comunicação, são o locus propício para a mudança. Um estudo ilustrativo é o de Waltereit (2006) acerca do desenvolvimento de marcadores discursivos em italiano a partir de verbos no imperativo, em que uma mudança por implicatura tem início quando os falantes usam elementos de chamada de atenção em contextos distintos daquele de seu uso primário, por exemplo, guarda! (olha!), quando não há o que olhar, e diciamo (digamos), quando os interlocutores não estão engajados em fala simultânea.

Outros estudiosos de gramaticalização, além de levarem em conta motivações cognitivo-comunicativas, já consideravam também motivações sociolinguísticas. Bisang (1998), por exemplo, afirma que as motivações para a mudança linguística envolvem o papel do falante e do ouvinte e também fatores sociolinguísticos (comunidades linguísticas e diferentes tipos de contato), sugerindo que esses fatores podem, inclusive, ser mais importantes que os semântico-pragmáticos, uma vez que, para que haja gramaticalização, é necessário que as mudanças individuais se espalhem para outros indivíduos. Androutsopoulos (1999), por sua vez, sinaliza para a importância da observação de grupos sociais ou de estilos linguísticos em que uma instância da gramaticalização ocorre, enfatizando o papel dos jovens na emergência de marcadores discursivos e gírias que têm o potencial de se tornarem habituais e se espalharem para uma comunidade de fala mais ampla.

\footnotetext{
${ }^{14}$ Gramaticalização entendida como "a mudança pela qual itens lexicais e construções passam em certos contextos a desempenhar funções gramaticais e, uma vez gramaticalizados, continuam a desenvolver novas funções gramaticais" (HOPPER; TRAUGOTT, 2003, xiii; grifos acrescidos). No original: "the change whereby lexical items and constructions come in certain linguistic contexts to serve grammatical functions and, once grammaticalized, continue to develop new grammatical functions"

${ }^{15}$ No original: "[...] change is the result of strategic interaction, specifically of choice-making on the part of speakers/writers in interactional negotiation with addressees/readers."
} 
Nos estudos sobre gramaticalização, são propostas diferentes trajetórias de mudança, a depender da perspectiva assumida pelos autores. Interessa-nos trazer à tona os clines de mudança delineados por Traugott (1982, 1989, 1999, 2010b) e por Heine Claudi e Hunnemeyer (1991), tomando por base as funções da linguagem (ideacional, textual e interpessoal) postuladas por Halliday e Hasan (1976). Traugott (1982, 1989), renomeando as funções respectivamente como proposicional, textual e expressiva, sugere inicialmente o seguinte cline para as mudanças via gramaticalização: proposicional > (textual) > expressivo. Essa trajetória é, no entanto, questionada por Heine et al. (1991) sob o argumento de que o componente "expressivo" contempla apenas o falante (suas crenças e atitudes sobre o que é dito), deixando de lado o componente interacional voltado para o ouvinte, o que, segundo os autores, não corresponde à dimensão interpessoal postulada por Halliday e Hasan. Heine et al. (1991) propõem, então, a trajetória ideacional > interpessoal > textual para os itens em gramaticalização. ${ }^{16}$

Posteriormente, os estudos de Traugott (1999; 2010b) sobre os processos de (inter)subjetivização ampliam e redefinem vários aspectos ligados ao percurso inicialmente sugerido pela autora, ressaltando a necessária subdivisão do componente expressivo em duas dimensões - uma subjetiva e orientada para o falante e outra intersubjetiva e orientada para o ouvinte. Tal subdivisão possibilita o estabelecimento de uma trajetória de (inter)subjetivização, em que itens podem ser recrutados para codificar atitudes e crenças do falante (subjetivização) e, uma vez subjetivizados, podem seguir adiante codificando significados centrados no ouvinte (intesubjetivização). A autora pondera que o componente “interpessoal” considerado por Heine et al. (1991) diz respeito à intersubjetividade inerente ao ato de fala manipulativo em que um enunciado é endereçado de um falante a um ouvinte (no caso de perguntas e de comandos), e isso não inviabiliza o cline proposto por ela. ${ }^{17}$

Para ilustrar o que expusemos até aqui sobre como a dimensão interpessoal atravessa as discussões funcionalistas sobre gramaticalização, trazemos novamente à

\footnotetext{
${ }^{16}$ Heine et al. (1991) justificam sua proposta de trajetória com base no desenvolvimento de pronomes interrogativos como who? ou which? - em que há uma função interpessoal voltada para o ouvinte - para pronomes relativos, que desempenham função textual.

${ }^{17}$ Uma discussão mais densa dessa temática pode ser conferida em Rost Snichelotto e Görski (2011).
} 
pauta o trabalho de Valle (2014), que sugere que as mudanças ocorridas em relação ao uso de sabe? e entende? no direcional verbo de cognição > marcador discursivo tenham se iniciado em contextos plenamente interrogativos em que os itens funcionam como verbos plenos em atos de fala diretivos (Sabe/entendeu o que eu falei?). Antes de apresentar o artefato metodológico construído para captar estágios de gramaticalização desses itens interacionais, fazemos um parêntese para descrever brevemente o funcionamento dos MDs em diferentes planos e caracterizá-los como possível instância de gramaticalização.

Os MDs em geral, segundo Schiffrin (2001), podem atuar simultaneamente em vários planos discursivos: no cognitivo, em que se representam conceitos e ideias através da língua; no textual, em que se organizam formas dentro de unidades linguísticas maiores; no social/expressivo, em que estão em jogo identidades pessoais e sociais, atitudes do falante perante o uso linguístico e negociações entre falante e ouvinte. Considerando que o plano social/expressivo engloba atuações de natureza bastante distinta tomadas em conjunto, Valle (2014) propõe uma subdivisão em três planos: o social/identitário, que envolve aspectos identitários do indivíduo e sua inserção em grupos sociais; o das atitudes do falante, que corresponde a usos expressivos com componentes avaliativos (como polidez e modalização de enunciados), entre outros; e o interpessoal/interacional, em que está em foco a negociação falante-ouvinte na situação de comunicação. Em relação a sabe? e entende?, definidos por Urbano (2006) como marcadores basicamente interacionais, o plano interpessoal/interacional é tomado como central, embora, a depender do contexto de uso, um dos demais planos possa ganhar mais evidência (Figura 1). 
Figura 1: Os diversos planos de atuação dos marcadores interacionais

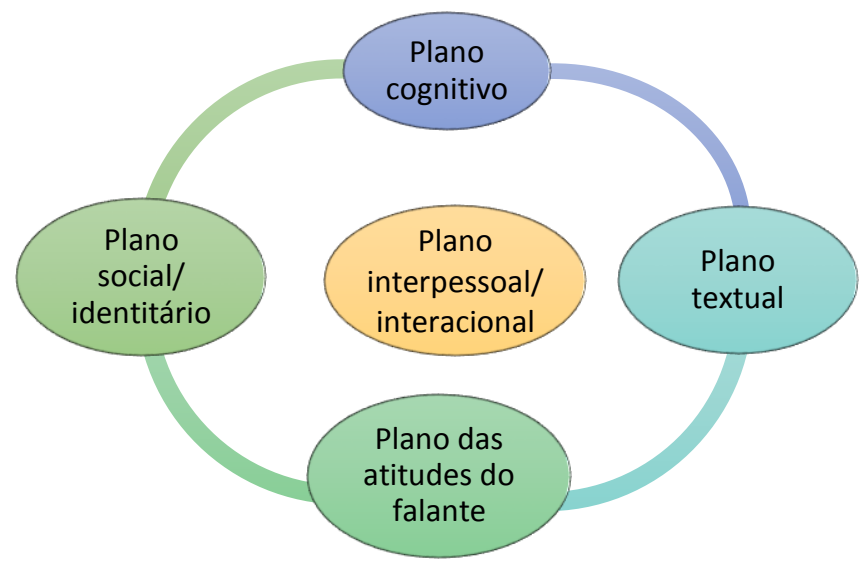

Fonte: Valle (2014, p. 226)

Assumimos, de acordo com Himmelmann (2004), que as mudanças que envolvem os MDs em tela acomodam-se, em alguma medida, aos seguintes critérios de gramaticalização: (i) expansão de classe hospedeira - aumento na coocorrência com diferentes tipos de unidades do discurso; (ii) expansão sintática - ampliação do escopo estrutural, por exemplo, em relação à posição; e (iii) expansão semântico-pragmática multifuncionalidade (principal traço definidor da gramaticalização, segundo o autor). Os itens passam a atuar como elementos focalizadores cumprindo, predominantemente no plano interpessoal/interacional, objetivos de natureza pragmática relacionados com o interlocutor e, no plano textual, papel na organização textual/discursiva (VALLE, 2014).

Partindo do pressuposto de que quanto mais se gramaticalizam, mais se distanciam tanto do item fonte quanto da estratégia que lhes deu origem - de acordo com o princípio da persistência ampliado ${ }^{18}$-, Valle (2014) constrói uma variável complexa para medir o grau de mudança categorial dos MDs em análise, através da integração de quatro grupos de fatores isolados que envolvem aspectos prosódicos, marcas de interação e aspectos morfofonéticos.

\footnotetext{
${ }^{18}$ O princípio da persistência proposto por Hopper (1991) prevê que, pelo menos em alguns estágios do processo de mudança, traços semânticos da forma original (item fonte) são mantidos na forma gramaticalizada (item alvo). Valle (2014) - inspirando-se em Waltereit (2011), que evoca a perspectiva do falante para explicar as mudanças do advérbio francês bien até seu uso como marcador discursivo acrescenta que as estratégias discursivas originais usadas pelos falantes também podem persistir no item alvo, ampliando assim esse princípio.
} 
A ideia é de estabelecer pontuação gradiente entre dois polos: (i) aquele onde estão itens menos avançados em termos de mudança categorial - ainda com forte carga interacional e ligados à estratégia discursiva e ao significado de origem (estando em maior evidência o plano interpessoal/interacioal) -, que ocorreriam acompanhados de presença de pausa posterior (ou anterior e posterior), resposta plena ou resposta plena com repetição de verbo, entonação de pergunta e extensão de forma por pergunta reduzida; (ii) e outro de itens em estágio mais avançado de mudança categorial - atuando com menor carga interacional e auxiliando na organização do discurso oral (estando em maior evidência o plano textual) -, que se apresentariam com ausência de pausas, ausência de estímulos do interlocutor, apagamento de entonação de pergunta e forma reduzida. Cada ocorrência de MD é pontuada conforme o Quadro 2.

Quadro 2: Pontuação dos fatores que compõem a variável complexa grau de mudança categorial

\begin{tabular}{|l|l|}
\hline Presença/ausência de pausas & Presença/ausência de estímulos do entrevistador \\
Zero - Ausência de pausas/ pausa & Zero - Ausência de estímulos/estímulos anteriores \\
anterior & 1,0 - Estímulos posteriores (Foi assim sabe? (Ahãm)) \\
1,o- Pausa posterior & 2,0 - Resposta Plena (Sim; Entendi; Sei) \\
\hline Entonação de pergunta & Redução/extensão de forma \\
Zero - Apagamento de entonação & Zero - Forma reduzida (tendeu?) \\
interrogativa & 1,0 - Forma plena (entendeu?) \\
1,0 - Presença de entonação & 1,5 - Extensão por presença de pronome (tu \\
interrogativa & entendeu?) \\
& 2,0 - Extensão por pergunta reduzida (tu sabes como \\
& é?) \\
\hline
\end{tabular}

Fonte: Adaptado de Valle (2014, p. 295)

O somatório dos pontos de cada grupo de fatores resulta no grau de mudança categorial do item, que oscila entre zero (mais avançado na mudança categorial) e seis (mais preso à categoria original), tal como em (2), em que entendesse? - com pausa posterior (1,o ponto), ausência de estímulos (zero ponto), entonação de pergunta (1,0 ponto) e forma plena (1,o ponto) - apresenta um somatório de três pontos e estaria em um grau de mudança categorial intermediário, nem tão vinculado à categoria de origem (verbo pleno) e nem tão avançado na mudança categorial (MD). 
(2) F: Ah, ele não aceitava "ah, vai alugar a minha casa, não sei o quê" (riso de E) aí o, né? até uma época (hes) quando ele alugou, ele chegou, ficou meio brabo porque não aceitou "ah, porque não sei o quê, agora tá morando aí, porque não sei o quê" "ah, nego, mas é pra ajudar, não sei o quê"... aí depois a gente se acostumou, né? agora- agora nem eu quero alugar e nem ele essa aqui, entendesse?... que muita gente diz assim "ó, guria, porque tu não aluga, pegar um dinheirão bom, não sei o quê", ah, não (VALLE, 2014, p. 295)

Em sua análise, ao efetuar o somatório a partir da pontuação dos fatores das variáveis independentes isoladas, a autora obteve resultados escalares oscilando entre zero e seis, os quais foram amalgamados de modo a resultarem em três fatores gradientes compondo a variável complexa: maior vínculo com a categoria de origem (com somatórios de 4,0 a 6,0), grau intermediário (de 2,0 a 3,5), maior grau de mudança categorial (de zero a 1,0). Os resultados indicam que, de modo geral, ambos os MDs concentram-se em grau intermediário de mudança, pois, se por um lado distanciam-se da estratégia discursiva que lhes deu origem - desacompanhados de pausas e estímulos/respostas posteriores -, por outro lado apresentam-se pouco erodidos e com entonação de pergunta (mesmo que leve). De modo mais específico, porém, entende? é favorecido com maior vínculo com a categoria de origem, apresentando-se mais atrelado ao plano interpessoal/interacional do que sabe?, que já parece carregar mais traços do plano textual.

Tais resultados podem ser correlacionados com as mudanças via gramaticalização e subjetivização, à medida que a dimensão interpessoal atravessa o desenvolvimento dos itens no direcional verbo > MD. Ao se deslocarem do uso como verbos plenos de cognição, por conta de forças pragmáticas, e passarem a atuar como elementos focalizadores, os itens em análise partem de um status mais lexical em direção a funções mais gramaticais, ligadas à organização textual - o que é consistente com o cline ideacional > interpessoal> textual (Cf. HEINE; CLAUDI; HÜNNEMEYER, 1991) e com noções mais alargadas do processo de gramaticalização (cf. TRAUGOTT, 1995; HOPPER; TROUGOTT, 2003; HIMMELMANN, 2004; WALTEREIT; DETGES, 2007; TRAUGOTT, 2008; 2010a; HEINE, 2018; entre outros). Além disso, à medida que os RADs atuam como elementos de focalização - usados pelo falante para direcionar a atenção do ouvinte a 
porções discursivas que julga merecerem maior destaque -, também parecem estar inseridos em um processo de subjetivização em que há o desenvolvimento de significados que expressam a atitude do falante em relação ao mundo comunicativo do evento de fala; ou seja, fica em evidência a função expressiva.

Detivemo-nos, nesta seção, a colocar em perspectiva um subgrupo de MDs, os RADs - elementos exemplares para ilustrar a dimensão interpessoal da linguagem -, admitindo a possibilidade de seu funcionamento ser explicado à luz da gramaticalização vista como expansão. Heine (2018, p. 43) respalda essa posição ao afirmar "não ter problemas em chamar MDs de marcadores gramaticais"19.

De modo similar ao que foi feito na seção precedente, apresentamos as etapas da elaboração de uma variável independente complexa, cujos fatores resultam do somatório de quatro traços, nesse caso para medir o grau de mudança categorial dos itens em questão, tomando esse resultado como evidência que autoriza a interpretação desse fenômeno discursivo como uma instância de gramaticalização.

Vale registrar que, na literatura mais recente sobre o desenvolvimento de MDs, a discussão acerca da definição e do status categorial desses itens (marcadores gramaticais ou marcadores pragmáticos?) e do tipo de processo de mudança envolvido (gramaticalização, ou pragmatização/discursivização?) tem ocupado um espaço significativo (cf. FISHER, 2006; DIEWALD, 2011; DEGAND; CORNILLIE; PIETRANDREA, 2013; HEINE, 2013; 2018; BRINTON, 2017; entre outros). Não vamos fomentar essa discussão aqui, mas essa constatação reforça a importância de continuar explorando o papel da dimensão interpessoal da linguagem na mudança. No caso dos RADs aqui examinados, consideramos que estratégias interacionais iniciais envolvidas no uso de saber e entender em contextos de perguntas diretas são fundamentais para o desenvolvimento de tais itens (verbos > MDs) e para sua atuação multifuncional.

\section{Considerações finais}

\footnotetext{
${ }^{19}$ No original: "we have no problems calling DMs grammatical markers"
} 
Neste artigo, buscamos iluminar a dimensão interpessoal da linguagem na Sociolinguística Variacionista e na Gramaticalização. Verificamos que (i) embora a sociolinguística laboviana reconheça a importância dessa dimensão, seu foco de interesse recai sobre a figura do falante e sua produção linguística em entrevistas; (ii) diferentemente, os estudos funcionalistas de gramaticalização, especialmente em sua faceta de expansão, imputam à situação comunicativa, particularmente à interação falante-ouvinte, um papel crucial na mudança linguística.

Considerando que: (i) a variação e a mudança são sensíveis à dimensão interpessoal; (ii) as pesquisas variacionistas têm pouco explorado metodologicamente essa dimensão; (iii) as pesquisas em gramaticalização sobre o desenvolvimento de MDs têm se dedicado basicamente a análises qualitativas; procuramos apresentar dois artefatos metodológicos construídos passo a passo como variáveis independentes complexas cujos fatores agregam, cada um deles, um conjunto de traços multidimensionais, com vistas a uma análise quantitativa. Mostramos, mediante a operacionalização de tais variáveis independentes, que os resultados evidenciam, por um lado, a correlação entre o uso dos RADs sabe? e entende? e aspectos interacionais que circundam as entrevistas sociolinguísticas; por outro lado, a correlação entre esses marcadores e os graus de mudança categorial envolvidos em seu processo de gramaticalização. Embora não tenha sido possível, dadas as limitações de espaço, correlacionar claramente a multifuncionalidade e a trajetória dos itens às funções da linguagem, é possível inferir do que foi apresentado que, a partir de uma função interpessoal, o significado interacional dos itens vai se enfraquecendo e o significado expressivo e/ou o significado textual vão se fortalecendo rumo a um uso mais gramaticalizado. No caso em questão, sabe? se encontra mais adiantado do que entende? em seu percurso de mudança.

Concluímos este artigo com a crença de que há muito a ser explorado ainda no universo de elementos linguísticos que desempenham funções pragmáticas/ discursivas, considerando a correlação entre processos de variação e mudança e a dimensão interpessoal da linguagem. 


\section{Referências}

ANDROUTSOPOULOS, J. K. Grammaticalization in young people's language: the case of German. Belgian Journal of Linguistics. v. 13, p. 155-176, 1999.

BISANG, W. Grammaticalization and language contact, constructions and positions. In: RAMAT, A. G. e HOPPER, P. J. (Eds.) The limits of grammaticalization. Amsterdam: John Benjamins, 1998. p. 13-58.

BELL, A. Back in style: reworking audience design. In: ECKERT, P.; RICKFORD, J. R. (Eds.). Style and Sociolinguistic Variation. Cambridge: Cambridge University Press, 2001. p. 139-169.

BRINTON, L.; TRAUGOTT, E. C. Lexicalization and language change. Cambridge: Cambridge University Press, 2005.

BRINTON, L. The evolution of pragmatic markers in English: pathways of change. Cambridge: Cambridge University Press, 2017.

BÜHLER, K. Teoría del lenguaje. Trad. de Julián Marías. Madrid: Revista de Occidente. 1961 [1934].

BYBEE, J. L. From usage to grammar: the mind's response to repetition. Language, v. 82, n. 4, 711-733, 2006.

COELHO, I. L.; NUNES DE SOUZA, C. M. Uma proposta metodológica para o tratamento da variação estilística em textos escritos. In: GÖRSKI, E. M.; COELHO, I. L.; NUNES DE SOUZA, C. M. (Orgs.) Variação estilística: reflexões teórico-metodológicas e propostas de análise. Florianópolis: Insular, 2014. p. 163-199.

DEGAND, L.; CORNILliE, B.; PIETRANDREA, P. Modal particles and discourse markers: two sides of the same coin? In: . Discourse markers and modal particles: categorization and description. Amsterdam: John Benjamins, 2013, p. 01-18.

DIEWALD, G. Pragmaticalization (defined) as grammaticalization of discourse functions. Linguistics 49 (2), p. 365-90, 2011. 
------. Context types in grammaticalization as constructions. Constructions, SV19/2006. Disponível em:

<https://journals.linguisticsociety.org/elanguage/constructions/article/view/24.html> ECKERT, P. Meaning and linguistic variation: The third wave in sociolinguistics. Cambridge: Cambridge University Press, 2018.

------. Third wave variationism. 2016. Disponível em:

<http://www.oxfordhandbooks.com/view/10.1093/oxfordhb/9780199935345.001.0oo1/o xfordhb9780199935345-e-27>.

------. Three waves of variation study: the emergence of meaning in the study of sociolinguistic variation. Annual Review of Anthropology, n. 41, p. 87-100, 2012.

FISCHER, H. (ed.) Approaches to Discourse Particles. Amsterdam: Elsevier. 2006

GIVÓN, T. On understanding grammar. New York: Academic Press, 1979.

------. English grammar: a function-based introduction, v. 1. Amsterdam: John Benjamins, 1993.

------. Bio-Linguistics. The Santa Barbara Lectures. Amsterdam: John Benjamins, 2002. GÖRSKI, E.; TAVARES, M. A. O objeto de estudo na interface variação gramaticalização. In: BAGNO, M.; CASSEB-GALVÃO, V.; REZENDE, T. F. (Orgs.) Dinâmicas funcionais da mudança linguística. São Paulo: Parábola. 2017· p. 35-63.

GÖRSKI, E. M.; VALLE, C. R. M. A variação estilística em entrevistas sociolinguísticas: uma (re)leitura do modelo laboviano. In: GÖRSKI, E. M.; COELHO, I. L.; NUNES DE SOUZA, C. M. (Orgs.) Variação estilística: reflexões teórico-metodológicas e propostas de análise. Florianópolis: Insular, 2014. p. 67-92.

HALLIDAY, M.A.K.; HASAN, R. Cohesion in English. London: Longman, 1976.

HEINE, B. Are there two different ways of approaching grammaticalization? In: HANCIL, S.; BREBAN, T.; LOZANO, J. V. (Eds.) New trends in grammaticalization and language change. Amsterdam: John Benjamins, 2018. p. 23-54.

------. On discourse markers: grammaticalization, pragmaticalization, or something else? Linguistics $5^{1}$ (6), p. 1205-1247, 2013.

-----; KALTENBOCK, G.; KUTEVA, T.; LONG, H. An outline of Discourse Grammar. In: BISCHOFF, S.T; JANY, C. (Eds.) Functional approaches to language. Berlin: De Gruyter Mouton, 2013. p. 155-206. 
------; CLAUDI, U.; HÜNNEMEYER, F. Grammaticalization: a conception framework. Chicago: University of Chicago Press, 1991.

------; KUTEVA, T. The genesis of grammar: a reconstruction. New York: Oxford University Press, 2007.

HIMMELMANN, N. P. Lexicalization and grammaticalization: Opposite or orthogonal? In: BISANG, W.; HIMMELMANN, N.; WIEMER, B. (Eds.). What makes grammaticalization? A look from its fringes and its components. Berlin: De Gruyter Mouton, 2004. p. 19-40.

HOPPER, P. On some principles in the grammaticalization. In: TRAUGOTT, E. C.; HEINE, B. (Eds.) Approaches to grammaticalization: focus on theoretical and methodological issues. Amsterdam: John Benjamins, 1991. v. 1 e 2., p. 7-35. . Emergent grammar. In: Berkeley Linguistics Society, n. 13, p. 139-157, 1987. Disponível em:

https://www.researchgate.net/publication/272816392 Emergent Grammar/link/56755f 2do8ae502c99cdedff/download

HOPPER, P.; TRAUGOTT, E. C. Grammaticalization. 2. ed. Cambridge: Cambridge University Press, 2003.

JAKOBSON, R. Linguística e poética. In: Linguística e comunicação. São Paulo: Cultrix, 1974 [1960]. p. 118-162.

LABOV, W. Where does the linguistic variable stop? A response to Beatriz Lavandera. Working Papers in Sociolinguistics, Southwest Educational Development Laboratory, Austin, n. 44, 1978. 23p.

LABOV, W. The anatomy of style-shifting. In: ECKERT, P.; RICKFORD, J. R. (Eds.) Style and sociolinguistic variation. Cambridge: Cambridge University Press, 2001. p. 85-108. LABOV, W. Some sociolinguistic principles. In: PAULSTON, C. B.; TUCKER, G. R. (Orgs.) Sociolinguistics: the essential readings. Oxford: Blackwell, 2003 [1969]. p. 234250.

LABOV, W. Padrões Sociolinguísticos. Trad. de Marcos Bagno; Maria Marta Pereira Scherre; Caroline Rodrigues Cardoso. São Paulo: Parábola, 2008 [1972].

LABOV, W. Principles of linguistic change. v. 3: Cultural and Cognitive Factors. Oxford: Wiley-Blackwell, 2010. 
LEHMANN, C. Thoughts on grammaticalization. $2^{\underline{a}}$. rev. ed. Munich: Lincom Europa. 1995 .

REIS, M. S. dos. Atos de fala não declarativos de comando na expressão do imperativo: a dimensão estilística da variação sob um olhar funcionalista. 2003. 216 f. Tese (Doutorado em Linguística) - Programa de Pós-Graduação em Linguística, Universidade Federal de Santa Catarina, Florianópolis, 2003.

ROST SNICHELOTTO, C. A.; GÖRSKI, E. M. (Inter)subjetivização de marcadores discursivos de base verbal: instâncias de gramaticalização. Alfa: Revista de linguística. São Paulo, v. 55, n. 2, p. 423-455, 2011.

SACKS, H., SCHEGLOFF, E.; JEFFERSON, G. A simplest systematics for the organization of turn taking for conversation. Language, v. 50, n. 4, p. 696-735, 1974.

SANKOFF, D.; TAGLIAMONTE, S.; SMITH, E. Goldvarb X: A variable rule application for Macintosh and Windows. Toronto: Department of Linguistics; Ottawa: Department of Mathematics, 2005. Disponível em: http://individual.utoronto.ca Ltagliamonte/goldvarb.htm

SCHIFFRIN, D. Discourse markers: language, meaning and context. In: ------; TANNEN, D.; HAMILTON, H. (Eds.). The handbook of discourse analysis. Malden, MA: Blackwell, 2001. p. 54-75.

STURTEVANT, E. H. An introduction to linguistic science. New Haven: Yale University Press, 1947 .

TAVARES, M. A.; GÖRSKI, E. M. Variação e sociofuncionalismo. In: MARTINS, M. A.; ABRAÇADO, J. (Orgs.). Mapeamento sociolinguístico do português brasileiro. São Paulo: Contexto, 2015. p. 249-270.

TRAUGOTT, E. C. From propositional to textual and expressive meanings: some semantic-pragmatic aspects of grammaticalization. In: LEHMMAN, W. P.; MALKIEL, Y. (Orgs.). Perspectives on Historical Linguistics. Amsterdam: John Benjamins, 1982. p. 245271.

; KÖNIG, E. The semantics-pragmatics of grammaticalization revisited. In: TRAUGOTT, E. C.; HEINE, B. (Eds.). Approaches to grammaticalization: focus on theoretical and methodological issues. Amsterdam: John Benjamins, v. 1 e 2, 1991. p. 189218. 
------.The role of the development of discourse markers in a theory of grammaticalization. Manchester: Stanford University, p. 1-29, 1995.

------. From subjectification to intersubjectification. Anais do Workshop on Historical Pragmatics - Fourteenth International Conference on Historical Linguistics: Vancouver, Canada, jul. 1999.

------. From etymology to historical pragmatics. In: MINKOVA, D.; STOCKWELL, R. (Eds.). Studying the History of the English Language: Millennial perspectives. Berlin: Mouton de Gruyter, 2002. p. 19-49.

------. All that he endeavoured to prove was...e $:$ On the emergence of grammatical constructions in dialogic contexts. In: COOPER, R..; KEMPSON, R. (Orgs.). Language in Flux: Dialogue Coordination, Language Variation, Change and Evolution. Londres: Kings College Publications, 2008. p. 143-177. Disponível em: <http://web.stanford. edu/ traugott/resources/TraugottCooperKempson.pdf>.

------. Grammaticalization. In: LURAGHI, S.; BUBENIK, V. (Orgs.). Continuum companion to historical linguistics. London/New York: Continuum International Publishing Group, 2010a. p. 269-283.

------. Revisiting subjectification and intersubjectification. In: DAVIDSE, K.; VANDELANOTTE, L.; CUYCKENS, H. (Eds.) Subjectification, Intersubjectification and Grammaticalization, Berlin: De Gruyter Mouton, 2010b. p. 29-70. Disponível em: <http://web.stanford.edu/ -traugott/ resources/TraugottDavidseIntersbfn.pdf>;.

-----; DASHER, R. Regularity in Semantic Change. Cambridge: Cambridge University Press, 2002.

URBANO, H. Marcadores discursivos basicamente interacionais. In: JUBRAN, C. C. A. S.; KOCH, I. G. V. (Orgs.). Gramática do português culto falado no Brasil. v. 1. Construção do texto falado. Campinas: Editora da UNICAMP, 2006. p. 497-528.

VALLE, C. R. M. Sabe? não tem? entende?: itens de origem verbal em variação como requisitos de apoio discursivo. 2001. 183f. Dissertação (Mestrado em Linguística) Programa de Pós-graduação em Linguística, Universidade Federal de Santa Catarina, Florianópolis, 2001.

------. Multifuncionalidade, mudança e variação de marcadores discursivos derivados de verbos cognitivos: forças semântico-pragmáticas, estilísticas e identitárias em 
competição. 2014. 415f. Tese (Doutorado em Linguística). Programa de Pós-graduação em Linguística, Universidade Federal de Santa Catarina, Florianópolis, 2014. ------; GÖRSKI, E, M. A construção de uma variável estilística complexa para medir a configuração da entrevista sociolinguística. Dossiê "Percepções sociolinguísticas e atitudes: os significados sociais da variação". Todas as Letras - Revista de Língua e Literatura, São Paulo, v.18, n. 2, p. 30-45, 2016.

WALTEREIT, R. The rise of discourse markers in Italian: A specific type of language change. In: FISCHER, K. (Ed.). Approaches to Discourse Markers. Oxford: Elsevier, 2006. p. 61-76.

------. Grammaticalization and Discourse. In: NARROG, H.; HEINE, B. (Eds.). The Oxford Handbook of Grammaticalization. New York: OUP, 2011, p. 413-423.

------; DETGES, U. Different functions, different histories. Modal particles and discourse markers from a diachronic point of view. In: CUENCA, M. J. (Ed.). "Contrastive perspectives on discourse markers". Special issue of Journal of Catalan Linguistics, v. 6, p. 61-82, 2007.

Recebido em 24/07/2020.

Aprovado em 18/12/2020. 